\title{
Characteristics of cholesterol absorption by human gall bladder: relevance to cholesterolosis
}

\author{
M R JACYNA, P E ROSS, M A BAKAR, D HOPWOOD, * I A D BOUCHIER \\ From the Departments of Medicine and ${ }^{*}$ Pathology, Ninewells Hospital and Medical School, Dundee, Scotland
}

SUMMARY The characteristics of cholesterol uptake by 83 human gall bladders (obtained at chole- $\vec{\omega}$ cystectomy) were studied with a modified Ussing technique. Real and artificial biles labelled with $14 \mathrm{C}$-cholesterol and $3 \mathrm{H}$-dextran (the latter to correct for adherent mucosal bile) were used; all gall ${ }^{\circ}$ bladders absorbed cholesterol (average $3.5 \mathrm{nmol} / \mathrm{cm}^{2} /$ minute). Recovery of the absorbed cholesterol of from the tissue showed that about $4 \%$ was esterified over 60 minutes. In artificial bile the rate of absorption of cholesterol increased as the bile saturation index rose, but became constant once $\stackrel{f}{f}$

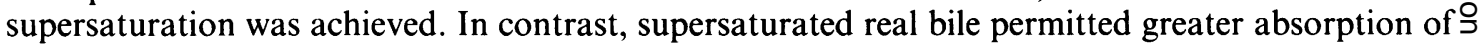
cholesterol, possibly due to enhanced cholesterol solubilisation.

Preincubation of gall bladder tissue in sodium cyanide $(5 \mathrm{mM})$ caused a $30 \%$ reduction in cholesterol uptake indicating that, although absorption is predominantly a "passive" process, there is a partial "active" component. There were no pronounced differences in the rate of cholesterol absorp- $₫$ tion as gall bladders became more diseased, but there was a reduction in the amount of cholesterol ${ }^{\text {* }}$ ester formed.

Cholesterolosis of the human gall bladder is common $^{12}$ and is characterised by the accumulation of free $^{3}$ and esterified ${ }^{4}$ cholesterol and triglycerides 5 in the mucosa of the gall bladder wall. The most common symptoms are colicky epigastric pain and nausea, but vomiting and intolerance to specific foods also occur. ${ }^{1}$ The aetiology of this condition is poorly understood but is believed to be associated with absorption of cholesterol from the bile. ${ }^{15-7}$ Both the guinea pig $^{8}$ and human gall bladder ${ }^{9}{ }^{10}$ have been shown to absorb small but noticeable amounts of cholesterol from bile, and patients with cholesterolosis have a high biliary cholesterol content. ${ }^{57}$ This disorder may arise simply because of increased uptake of cholesterol from bile containing increased amounts of cholesterol. Uptake of cholesterol by the intestine is predominantly a passive process, ${ }^{11}$ but no data exist on the mechanism of cholesterol uptake by the gall bladder. It has been suggested, however, that uptake of cholesterol by the gall bladder may occur via endocytosis, ${ }^{12}$ a transport process requiring energy.

This study was undertaken to identify the mechanism of cholesterol uptake by the human gall bladder epithelium, and also to study the effects of disease on this process.

Accepted for publication 11 December 1986

\section{Material and methods}

Cholesterol ( $99+\%$ pure), sodium bile salts, and L- $\alpha-\overrightarrow{\vec{B}}$ phosphatidyl choline (egg yolk type 1X-E) were 3 obtained from Sigma Chemicals, Poole, Dorset.

Silica gel was obtained from Andermann and? Company Ltd, Surrey. OV 210 was purchased from Chromotography Services, The Wirral, Merseyside.

Liquid scintillation fluid (Cocktail " $T$ " emulsifier) and all other chemicals not listed were analyticalio reagent grade obtained from British Drug Houses 3 Ltd, Poole, Dorset. Krebs-Ringer bicarbonate buffer (pH 7.4) with added glucose (KRBG) was prepared as described previously. ${ }^{13}$

The following radionuclides were obtained from Amersham International: 14C-cholesterol, 3H-Dex- No tran, and 14C-Sitosterol. Lipids were purified by thin layer chromatography before use.

HUMAN GALL BLADDERS

A total of 83 human gall bladders were studied: these had been obtained at the time of cholecystectomy undertaken for the usual medical indications. The gall ${ }^{+}$ bladders were received within 10 minutes of ligation 0 of the cystic artery and immediately placed in oxygen- $\frac{\vec{\Phi}}{\mathbb{0}}$

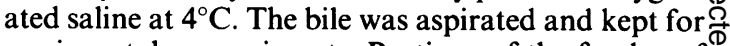
use in uptake experiments. Portions of the fundus of $\stackrel{D}{2}$ the gall bladder were cut after gentle washing with? 
saline to remove surface bile and debris; ulcerated or "torn" mucosa was not used. The serosal tissue was removed by blunt dissection, and the tissue was mounted in a modified Ussing chamber. The remainder of the gall bladder was assessed by a pathologist (DH) for the degree of chronic cholecystitis. The gall bladders were assessed and graded as normal (I), moderately (II), or severely (III) diseased, based on the appearance of the epithelial cells, the muscle layer thickness, the size and site of Rokitansky-Aschoff sinuses and the amount of chronic inflammatory infiltrate. $^{14}$ One entirely normal gall bladder (removed from a patient with idiopathic chronic pancreatitis) and two with isolated cholesterolosis were also studied.

\section{PREPARATION OF BILES}

Artificial bile was prepared from cholesterol, phosphatidylcholine, and bile salts. The bile salts consisted of six sodium salts mixed in the same proportions as found in human gall bladder bile - that is, glycine to taurine conjugates $3: 1$ and cholic, chenodeoxycholic, and deoxycholic $1 \cdot 5: 1 \cdot 0: 0 \cdot 7$, respectively. ${ }^{15} 16$ The molar ratio of phosphatidylcholine to bile salts was 0.20 and the total lipid concentration $10 \%$ (weight for volume).

The amount of cholesterol added to the biles was adjusted to produce biles whose lithogenic index ${ }^{17}$ ranged from $0 \cdot 1-2 \cdot 1$ (cholesterol concentration $1-14 \mu \mathrm{mol} / \mathrm{ml})$. Normal $(0 \cdot 154 \mathrm{M})$ sodium chloride was used to reconstitute the bile and the $\mathrm{pH}$ was adjusted to $7 \cdot 5 .{ }^{18}$ The bile solutions were heated to $80^{\circ} \mathrm{C}$ for one hour to obtain isotropic solutions and then filtered through a $0.22 \mu \mathrm{m}$ filter (Millipore SA, Molshein, France). The resulting optically clear micellar suspensions were kept at $37^{\circ} \mathrm{C}$ until used in experiments. Real supersaturated gall bladder bile was used within 30 minutes of removal from the gall bladder. A trace amount of $3 \mathrm{H}$-dextran and $0.2 \mathrm{mci} / \mu \mathrm{mol}$ of $14 \mathrm{C}$-cholesterol was then added to both artificial and real biles to produce $14 \mathrm{C} / 3 \mathrm{H}$ counts in the range $0 \cdot 1$ to $0 \cdot 5 .^{19}$

To compare cholesterol and $\beta$-sitosterol absorption artificial bile was made exactly as above, except $\beta$-sitosterol $(1 \mu \mathrm{mol} / \mathrm{ml})$ was used instead of cholesterol. This was compared with artificial bile containing cholesterol at an identical concentration $(1 \mu \mathrm{mol} / \mathrm{ml}$ : lithogenic index $=0 \cdot 1)$.

All biles were assayed for lipid content by the following methods: cholesterol, $\beta$-sitosterol, and bile salts by gas-liquid chromatography, ${ }^{20}$ and phospholipids by a spectrophotometeric assay. ${ }^{21}$

\section{CHOLESTEROL ABSORPTION}

Mucosal absorptive function was studied using a modified flux chamber, as originally described, by
Ussing and Zerahn to measure sodium flux and various electrical variables across isolated frog skin. ${ }^{22}$ Because no electrical measurements were performed, the device was modified and consisted simply of two perspex hemichambers, which functioned as separate compartments when a section of gall bladder mucosa was interposed between. The volume of each hemichamber was $2 \mathrm{ml}$ and $0.2 \mathrm{~cm}^{2}$ of gall bladder mucosa was exposed to both bathing solutions. The mucosal side of the gall bladder was exposed to $2 \mathrm{ml}$ of real or artifical bile at $37^{\circ} \mathrm{C}$ for varying periods of time, up to 90 minutes.

The serosal compartment was filled with KRBG and stirred and oxygenated by continuous bubbling with $95 \%$ oxygen and $5 \%$ carbon dioxide. The entire chamber was surrounded by a thermostatic water jacket which maintained the chamber contents at $37^{\circ} \mathrm{C}$. Four chambers were used per gall bladder to assess absorption of cholesterol from artificial biles of increasing lithogenic index. In some experiments absorption of cholesterol from real bile and $\beta$-sitosterol absorption from artificial bile were also studied.

Samples of fluid from the serosal side were removed (and replaced with fresh KRBG) to measure any radioactivity that had passed through the tissue from the mucosal side. At the end of an experiment the tissue sample was removed, rinsed for three to five seconds in cold saline, and blotted on dry filter paper for two seconds. The tissue was then divided into two; half of the sample was saponified in $0.5 \mathrm{ml}$ of 0.75 $\mathrm{NaOH}$ at $110^{\circ} \mathrm{C}$ until dissolved, and the $\mathrm{pH}$ then readjusted to 7.0. The saponified tissue sample, serosal fluid, and aliquots of bile were then placed in individual plastic scintillation phials and $4.5 \mathrm{ml}$ of cocktail " $T$ " scintillation fluid was added.

The radioactivity of the samples was determined using a Packard PLD Prias TRI-CARB liquid scintillator with preset windows and quench correction. The remaining half of the tissue was homogenised and the lipids extracted according to the method of Folch. ${ }^{23}$ Lipid analysis of the homogenate was then performed by thin layer chromatography on silica glass plates with the solvent system n-heptane: diethylether: chloroform: acetic acid, 25:8:6:1. The spots corresponding to cholesterol and cholesterol ester were scraped into scintillation phials and assayed for radioactivity as described above. In experiments assessing the effect of sodium cyanide on cholesterol absorption, the tissue was preincubated for 10 minutes in oxygenated $\mathrm{KRBG}$ at $37^{\circ} \mathrm{C}$ containing $5 \mathrm{mM}$ sodium chloride before the experiments were performed.

DETERMINATION OF CHOLESTEROL IN

ADHERENT BILE

At the end of an experiment the gall bladder mucosa 
was rinsed in saline. In spite of this some mucosal fluid (bile) always remained adherent to the surface of the mucosa and thus added radioactive counts to the intracellular (absorbed) cholesterol. To eliminate this overestimation $3 \mathrm{H}$-dextran used as a non-absorbable marker was assumed to be homogenously distributed between the bulk phase of the bile and the adherent fluid. The volume of the adherent layer was determined for each experiment, and the amount of cholesterol (or $\beta$-sitosterol) present in that volume was then calculated and subtracted from the total apparent absorption value for cholesterol. Thus a more realistic value was obtained for the amount of cholesterol absorbed.

\section{STATISTICAL METHODS}

All data are presented as mean (SEM), with the number of gall bladders shown in parentheses. As the data did not conform to a normal distribution nonparametric tests were used. Unpaired data were analysed by the Mann-Whitney $U$ test, and the Wilcoxon test was used for paired data. A p value of 0.05 was regarded as significant.

\section{Results}

Uptake of cholesterol from artificial saturated bile from 48 gall bladders (lithogenic index $=1.0$ ) was plotted against time. Fig 1 shows that the rate of uptake of cholesterol was constant over the first 20 minutes of the experiment (at about $3.5 \mathrm{nmol} /$ $\mathrm{cm}^{2} /$ minute). After 20-30 minutes of the experiment had elapsed, however, tissue levels of cholesterol became constant at about $80-100 \mathrm{nmol} / \mathrm{cm}^{2}$. This plateau in mucosal cholesterol values suggests that an equilibrium had been reached between cholesterol uptake into the mucosa and loss back into the bile and serosal compartment.

The appearance of cholesterol in the serosal com-

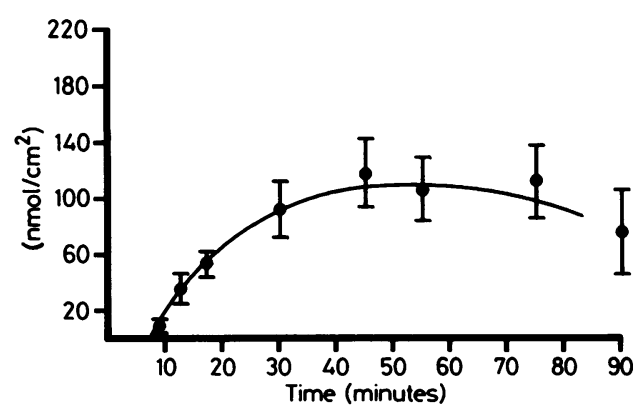

Fig 1 Uptake of cholesterol by gall bladder mucosae $\left(\mathrm{nmol} / \mathrm{cm}^{2}\right)$ from artificial saturated bile (lithogenic index $=$ 1.0) with time (minutes). Each point represents mean SEM of six gall bladders.

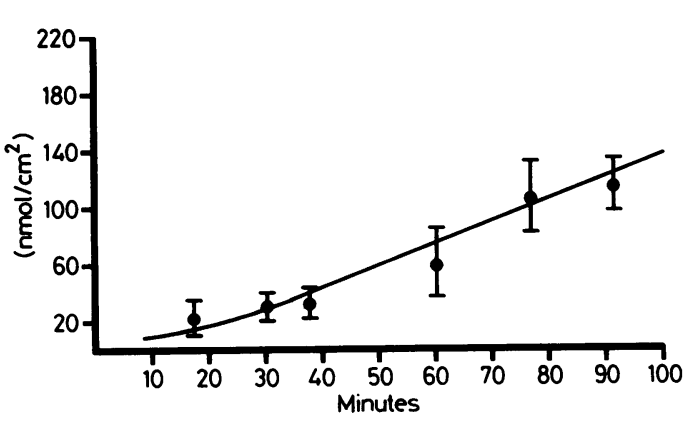

Fig 2 Transport of cholesterol into serosal fluid $\left(\mathrm{nmol} / \mathrm{cm}^{2}\right.$ with time (minutes). Each point represents mean SEM of six gall bladders.

partment was plotted against time (fig 2) and was lin- of ear over 90 minutes at about $1.0 \mathrm{nmol} / \mathrm{cm}^{2} /$ minute. N This indicates that once equilibrium is achieved, only 0 one third of the cholesterol absorbed by the mucosa is secreted into the serosa, and that the remaining two thirds is exchanged for mucosal cholesterol, which is then simply returned back to the bile.

In artificial biles the rate of absorption of cholesterol increased as the bile cholesterol concentration rose (fig 3) until the bile became saturated with cholesterol (lithogenic index $=1 \cdot 0$, cholesterol concentration $8.5 \mu \mathrm{mol} / \mathrm{ml}$ ). Above this point-that is, supersaturated bile - any further increase in the biliary cholesterol concentration (and corresponding $\stackrel{\square}{\perp}$ lithogenic index) did not result in a further increase in $\overrightarrow{\vec{B}}$ the rate of cholesterol absorption. In addition, it was 3 macroscopically observed ${ }^{24}$ that all artificial supersaturated biles had formed cholesterol microcrystals by the end of experiments. Uptake of cholesterol from real supersaturated bile, however, was shown to ? exceed that from artificial bile of similar cholesterol saturation (fig 3).

Uptake of cholesterol by the mucosa and appearance in the serosal fluid were also studied and compared in gall bladders with increasing degrees of $\stackrel{\circ}{\triangle}$ cholecystitis. As the degree of chronic cholecystitis $\rightarrow$ increased, there were no significant differences noted in either uptake or serosal exit of cholesterol (table 1). N Uptake and exit of cholesterol from the normal and cholesterolotic gall bladders fell within the same range as that in the cholecystitic gall bladders.

The percentage of absorbed cholesterol that was? esterified after 60 minutes in the Ussing chamber was 0 calculated for $\mathbf{4 0}$ gall bladders. The results indicate $\mathbb{D}$ that $3.7 \%$ of the absorbed cholesterol was esterified $\stackrel{?}{?}$ during this period (table 2). The amount of choles- $T$ terol ester formed by the gall bladder mucosa, how- $\frac{O}{\mathbb{D}}$ ever, decreased as the degree of chronic cholecystitis increased $(\mathrm{p}<0.05)$.

Table 3 shows the effect of incubating gall bladder 


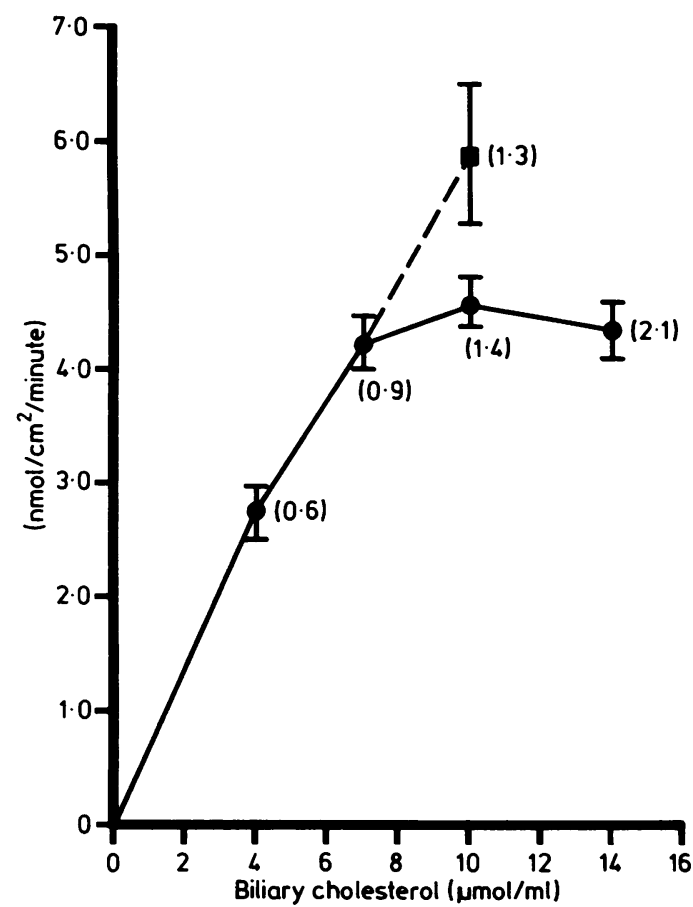

Fig 3 Cholesterol absorption rates $\left(\mathrm{nmol} / \mathrm{cm}^{2} /\right.$ minute) from

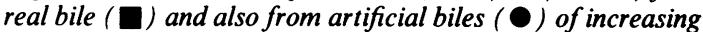
cholesterol concentration $(\mu \mathrm{mol} / \mathrm{ml}$ ) (with lithogenic index shown in parentheses).

tissue in sodium cyanide before assessing cholesterol uptake. A $30 \%$ reduction in uptake of cholesterol occurred. Absorption of cholesterol and $\beta$-sitosterol from micellar solutions was also studied. The results show that there was no significant difference in the rate of absorption of these compounds when they were both present in identical concentration in bile: cholesterol has $4.8 \quad(0.4) \mathrm{nmol} / \mathrm{cm}^{2} /$ minute; and $\beta$-sitosterol $4.4(0.9) \mathrm{nmol} / \mathrm{cm}^{2} /$ minute.

\section{Discussion}

This study confirms previous work which showed that isolated human gall bladder tissue is able to absorb small but clinically important amounts of cholesterol from bile. In addition, this study also indicates that, although cholesterol uptake is predominantly a passive process, an active energy dependent process is also entailed. There was a $30 \%$ reduction in cholesterol uptake when gall bladder mucosa was preincubated in sodium cyanide, which is similar to the findings of in vitro studies in the intestine where metabolic inhibitors diminished the uptake of cholesterol by about $40 \% .^{25}$

Although cholesterol absorption by the intestine is believed to occur mainly by passive diffusion, ${ }^{11}$ it has been speculated that a cholesterol binding protein located in the enterocyte membrane may assist cholesterol uptake, ${ }^{26}$ and a similar cholesterol carrier may also be present in the gall bladder epithelium. Fluid phase endocytosis, however, has been observed in the gall bladder mucosa, ${ }^{12}$ and this represents a more likely energy dependent means of non-specific absorption. In the intestine studies have shown that cholesterol is selectively absorbed compared with other sterols, in particular $\beta$-sitosterol. ${ }^{27}$ The results of the present study, however, showed no significant difference between the rates of $\beta$-sitosterol and cholesterol absorption, and suggest a non-selective sterol absorptive pathway by the mucosa of the gall bladder.

The degree of chronic cholecystitis did not cause any changes in either uptake or serosal exist of cholesterol from these gall bladders. Even the most severely diseased gall bladders absorbed cholesterol at the same rate as the moderately inflamed and normal gallbladders.

Several other characteristics of cholesterol uptake were noted. In artificial biles the rate of cholesterol uptake depended more on whether the bile was saturated or not, rather than on the absolute biliary cholesterol concentration. This suggests that the limiting

Table 1 Mean (SEM) uptake of cholesterol by mucosae and transport into serosal fluid (nmol/ $\mathrm{cm}^{2} / \mathrm{minute}$ compared with degree of cholecystitis

\begin{tabular}{|c|c|c|c|c|c|c|c|}
\hline & \multicolumn{4}{|c|}{ Grade of disease } & \multirow{2}{*}{\multicolumn{3}{|c|}{ Cholesterolosis }} \\
\hline & $\begin{array}{l}\text { Normal } \\
\text { Norm }\end{array}$ & $\begin{array}{l}\text { II } \\
\text { Moderate }\end{array}$ & $\begin{array}{l}\text { III } \\
\text { Severe }\end{array}$ & $\begin{array}{l}\text { Entirely normal } \\
\text { (no gallstones) }\end{array}$ & & & \\
\hline $\begin{array}{l}\text { Mucosal cholesterol } \\
\text { uptake (nmol/cm²/minute) } \\
\text { Cholesterol transport } \\
\text { into serosal fluid } \\
\text { (nmol } / \mathrm{cm}^{2} / \text { minute) }\end{array}$ & $0.98(0 \cdot 16)$ & $1 \cdot 19(0 \cdot 20)$ & $1.02(0.12)$ & $1.00(0 \cdot 16)$ & $1 \cdot 10$ & $\begin{array}{l}1.08 \\
0.61\end{array}$ & $\begin{array}{l}\mathbf{p}=\mathbf{N S} \\
\mathbf{p}=\mathbf{N S}\end{array}$ \\
\hline
\end{tabular}


Table 2 Percentage of absorbed cholesterol esterified after 60 minutes compared with degree of cholecystitis

\begin{tabular}{ll}
\hline & $\begin{array}{l}\text { Percentage of } \\
\text { ester formed }\end{array}$ \\
\cline { 2 - 2 } Histological grade & Mean $($ SEM $)$ \\
\hline Grade I/II & $4.9(0.7) \%$ \\
Grade III & $2 \cdot 9(0 \cdot 4) \% \mathrm{p}<0.05$ \\
All grades & $3 \cdot 7(0.4) \%$ \\
\hline
\end{tabular}

Table 3 Effect of different preincubation media on uptake of cholesterol by gall bladder mucosae

\begin{tabular}{|c|c|c|}
\hline $\begin{array}{l}\text { Preincubation } \\
\text { media }\end{array}$ & $\begin{array}{l}\text { Cholesterol } \\
\text { uptake at } 30 \\
\text { minutes } \\
\left(\mathrm{nmol} / \mathrm{cm}^{2}\right) \\
\text { mean }(\mathrm{SEM})\end{array}$ & $\begin{array}{l}\text { Cholesterol } \\
\text { uptake at } 60 \\
\text { minutes } \\
\left(\text { nmol } / \mathrm{cm}^{2}\right) \\
\text { mean }(\mathrm{SEM})\end{array}$ \\
\hline \multirow{2}{*}{$\begin{array}{l}\text { KRBG alone } \\
\text { KRBG + sodium } \\
\text { cyanide }\end{array}$} & $210(28)$ & $316(56)$ \\
\hline & $150(19)$ & $199(36)$ \\
\hline
\end{tabular}

factor for cholesterol uptake resides within the bile itself and not the mucosa. The likeliest explanation is that it represents an artefact of supersaturated artificial biles, which have previously been shown to be more prone to cholesterol precipitation and crystal formation than real supersaturated biles. ${ }^{28}$

In this study all supersaturated artificial biles had formed cholesterol crystals by the end of experiments. Consequently, artificial biles had lower amounts of cholesterol in true micellar solution than real biles of equivalent cholesterol saturation and concentration, which have been shown to have enhanced cholesterol solubilising ability. These results indicate that the physicochemical presentation of biliary cholesterol has more influence on cholesterol uptake than changes in mucosal morphology. The amount of cholesterol ester that was formed by the mucosa, however, decreased as the tissue became more diseased. The reason for this may be that diseased tissue is less able to esterify cholesterol due to increased epithelial cell damage. Another possible explanation is the reduced number of mucosal folds (and consequently reduced number of cells per unit area) that are found with increasing degrees of cholecystitis. ${ }^{14}$

Supersaturated bile is present in both cholesterol cholelithiasis and cholesterolosis, ${ }^{7}$ but is also commonly found in "normal" people. ${ }^{29}$ In "normal" people, however, the degree of supersaturation and the absolute cholesterol concentration are lower than in patients with disease, ${ }^{29}$ and it may be that there is a critical supersaturation limit, above which either cholesterolosis or cholesterol gall stones may develop. As to which of these two pathological conditions develops may depend on the ability of the bile to keep cholesterol fully solubilised. Patients who are unable to fully solubilise cholesterol in supersaturated biles will develop crystals and go on to form gall stones. Patients with supersaturated bile who are able to keep cholesterol fully solubilised, however, may have increased mucosal cholesterol uptake (as our data indicate that real bile permits greater absorption of cholesterol than artificial bile) and could go on to develop cholesterolosis.

As well as participating in the development of cholesterolosis, cholesterol uptake by the mucosa may be associated with several other important changes in gall bladder mucosal physiology. Studies have shown that a rise in the cholesterol content of bile is promptly followed by certain specific changes in gall bladder function. These changes are: an increase in the fluid absorptive capacity of the mucosa ${ }^{30}$; a hypersecretion of mucus ${ }^{31}$; and a decrease in gall bladder emptying. ${ }^{32}$ These changes occur early, immediately after the rise in bile cholesterol has occurred, and before gall stones have had time to form. The increase in cellular cholesterol concentrations, which will follow uptake of cholesterol by the epithelia, will change cellular membrane fluidity and function. ${ }^{33}$ The importance of these functional changes has yet to be defined, but they may have a crucial role in the aetiology (or prevention of) diseases of the gall bladder.

We express our appreciation of the surgeons at Ninewells who supplied cholecystectomy specimens. Dr Peter Ross is in receipt of a Scottish Home and Health Department Grant. Mr Jacyna is a British Digestive Foundation Research Fellow.

\section{References}

1 Salmenkivi K. Cholesterosis of the gall-bladder: a clinical study based on 269 cholecystectomies. Acta Chir Scand 1964;324 (suppl):1-93.

2 Feldman M, Feldman M Jr. Cholesterosis of the gallbladder: an autopsy study of 165 cases. Gastroenterology 1954;27:641-8.

3 Koga A, Todo S, Nishimura M. Electron microscopic observations on the cholesterol distributed in the epithelial cells of the gallbladder. Histochemistry 1975;44:303-9.

4 Boyd LW. Studies on gall bladder pathology. Br J Chem 1923;234:466-8.

5 Tilvis RS, Aro J, Strandberg TE, Lempinen M, Miettinen TA. Lipid composition of bile and gallbladder mucosa in patients with acalculous cholesterolosis. Gastroenterology 1982; 82:607-15.

6 Tilvis RS, Aro J, Strandberg TE, Lempinen M, Miettinen TA. In vitro synthesis of triglycerides and cholesterol in human gall bladder mucosa. Scand J Gastroenterol 1982;17:335-40.

7 Acalovschi M, Dumitrascu D, Grigorescu M, Suciu A, Badea G, Paraian I. Pathogenetic interrelations between cholesterolosis and cholesterol gallstone disease. Review Roumanian Medecin 1983;21:175-9. 
8 Neiderhiser DH, Harmon CK, Roth PH. Absorption of cholesterol by the gall bladder. J Lipid Res 1976;17:117-24.

9 Ross PE, Bakar M, Jacyna MR, Hopwood D, Shepherd AN, Bouchier IAD. Does the gallbladder modify biliary lipid composition? In: Elias E, Murphy G, eds. Bile in health and disease: proceedings of the sixth British Society of Gastroenterology/ Smith Kline \& French international workshop 1985. Welwyn Garden City: SK \& F, 1986:51-3.

10 Jacyna MR, Ross PE, Hopwood D, Bouchier IAD. Absorption of cholesterol by the human gallbladder. Gut 1985;26:A1132.

11 Thomson ABR, Dietschy JM. Intestinal lipid absorption: major extracellular and intracellular events. In: Johnson LR, ed. Physiology of the gastrointestinal tract. New York: Raven Press, 1981:1147-220.

12 Hayward AF. Electron microscopic observations on absorption in the epithelium of the guinea-pig gallbladder. Z Zellforsch 1962;56:197-201.

13 Dawson RM, Elliott DC, Elliott WH, Jones KM. Data for biochemical research. 2nd Ed. London: Oxford University Press, 1969:507.

14 Symmers WS-C. Systemic pathology. Vol 3. 2nd ed. Edinburgh: Churchill Livingstone. 1978:1304-30.

15 Dam H, Kruse I, Kallehauge HE, Hartkopp OE, Kroghjenses M. Studies on human bile I. Composition of bladder bile from cholelithiasis patients and surgical patients with normal bile compared with data for bladder bile of hamsters on different diets. Scand J Clin Invest 1966;18:385-404.

16 Neiderhiser DH, Roth PH. Cholesterol solubilisation by solutions of bile salts and bile salts plus lecithin. Proc Soc Exp Biol Med 1968;128:221-5.

17 Thomas PJ, Hofmann AF. A simple calculation of the lithogenic index of bile; Expressing biliary lipid composition on rectangular co-ordinates. Gastroenterology 1973;65:698-700.

18 Levy PF, Smith BF, Lamont JT. Human gall bladder mucin accelerates nucleation of cholesterol in artificial bile. Gastroenterology 1984;87:270-5.

19 Herberg RJ. Statistical aspects of double isotope liquid scintillation counting by internal standard technique. Anal Chem 1964;36:1079-82.

20 Bateson MC, Ross PE, Murison J, Bouchier IAD. Effect of prolonged feeding with chenodeoxycholic acid on bile in patients with and without gallstones. Gut 1977;18:599-605.

21 Zilversmit DB, Davies AK. Microdetermination of plasma phospholipids by trichloroacetic acid precipitation. J Lab Clin Med 1950;35:155-60.
22 Ussing HH, Zerahn K. Active transport of sodium as the source of electric current in the short-circuited isolated frog-skin. Acta Physiol Scand 1951;23:110-27.

23 Folch J, Lees M. Sloane-Stanley GH. A simple method for the isolation and purification of total lipids from animal tissues. $J$ Biol Chem 1957;226:497-509.

24 Admirand WH, Small DM. The physico-chemical basis of cholesterol gallstone formation in man. $J$ Clin Invest 1968;47:1043-52.

25 Watanabe M, Oku T, Shidoji Y, Hosoya N. A new aspect on the mechanism of intestinal cholesterol absorption in Rat. $J$ Nutr Sci Viatminol 1981;27:209-17.

26 Chow SL, Hollander D. Initial cholesterol uptake by everted sacs of rat small intestine. Kinetic and thermodynamic aspects. Lipids 1978:13:239-45.

27 Shidoji Y, Watanabe M, Oku T, Muto Y, Hosoya N. Inhibition of beta-sitosterol on intestinal cholesterol absorption in rat using an in-vivo dual isotope ratio method. $J$ Nutr Sci Vitaminol 1980;26:183-8.

28 Holzbach RT. Kibe A, Thiel H, Howell JH, Marsh M, Hermann RE. Biliary proteins. Unique inhibitors of cholesterol crystal nucleation in human gall bladder bile. J Clin Invest 1984;73:35-45.

29 Holzbach RT. Marsh M, Olszewski M, Holan K. Cholesterol solubility in bile: evidence that supersaturated bile is frequent in healthy man. $J$ Clin Invest 1973;52:1467-76.

30 Conter RL, Roslyn JL, Porter-Fink V, DenBesten L. Gallbladder absorption increases during early cholesterol gallstone formation. Am J Surg 1986;151:184-91.

31 Lee SP, LaMont JT, Carey MC. Role of gallbladder mucus hypersecretion in the evolution of cholesterol gallstones. J Clin Invest 1981;67:1712-33.

32 Doty JE, Pitt HA, Kuchenbecker SL, DenBesten L. Impaired gall bladder emptying before gallstone formation in the prairie dog. Gastroenterology 1983;85:168-74.

33 Chapman D, Kramers MTC, Restall CJ. Cholesterol and biomembrane structure. In: Danielsson H, Sjovall J, eds. Sterols and bile acids. Amsterdam: Elsevier, 1985:159.

Requests for reprints to: Dr MR Jacyna, Department of Medicine, Ninewells Hospital and Medical School, Dundee, Scotland DDI 9SY. 